\title{
SISTEM INFORMASI MANAJEMEN
}

\section{PADA SWALAYAN DI TULUNGAGUNG}

\author{
OLEH : \\ RISMA ANANDA NUR M. \\ FAVIOLA ID’HARETNA SARI \\ AYSHA DIAH GARNIS P.
}

\begin{abstract}
ABSTRAKSI
Penelitian ini bertujuan untuk mendapatkan bukti empiris mengenai system informasi manajemen yang paling sering digunakan pada swalayan di KabupatenTulungagung. Metode penelitian dalam penelitian ini yaitu menggunakan data sekunder. Data sekunder merupakan data yang tidak berasal dari sumber utama. Data ini digunakan sebagai data pendamping data utama karena adanya hal-hal yang tidak ditemukan di data utama. Namun di beberapa penelitian lainnya, data sekunder ini menjadi satu-satunya sumber data. Kelebihan menggunakan metode ini yaitu sudah tersedia, mudah didapatkan, waktu dan biaya yang dibutuhkan untuk penelitian, untuk mengklasifikasi permasalahan, dan mengevaluasi data relatif lebih sedikit dibandingkan dengan pengumpulan data primer. Maka dari itu kita memilih untuk menggunakan data sekunder. Hasil penelitian ini menunjukkan bahwa yang paling sering digunakan pada swalayan di Tulungagung yaitu aplikasi POS. Seperti misalnya yaitu Bravo, Golden, Alfamart maupun Indomaret di Tulungagung semua menggunakannya. Dengan adanya sistem informasi ini, tidak hanya membuat proses menjadi otomatis, tetapi juga menciptakan tingkat akurasi yang tinggi, kecepatan dalam pelayanannya, menjadi pelengkap dalam kegiatan bisnis perusahaan dan berguna menghasilkan keunggulan kompetitif bagi perusahaan.
\end{abstract}

Kata kunci : Sistem informasi, swalayan, perusahaan. 


\section{ABSTRACTION}

This study aims to obtain empirical evidence regarding the management information system that is most often used in supermarkets in Tulungagung Regency. The research method in this research is using secondary data. Secondary data is data that does not come from the main source. This data is used as complementary data to the main data because there are things that are not found in the main data. However, in several other studies, this secondary data is the only source of data. The advantages of using this method are that it is readily available, easy to obtain, the time and cost required for research, to classify problems, and evaluate data is relatively less compared to primary data collection. Therefore we choose to use secondary data. The results of this study indicate that the most frequently used in supermarkets in Tulungagung is the POS application. For example, Bravo, Golden, Alfamart and Indomaret in Tulungagung all use it. With this information system, it not only makes the process automatic, but also creates a high level of accuracy, speed in service, becomes a complement to the company's business activities and is useful in generating a competitive advantage for the company.

Keywords: Information system, self-service, company. 


\section{PENDAHULUAN}

Dalam dunia usaha proses penjualan adalah suatu proses yang sangat important, yang menentukan siklus hidup kelangsungan perusahaan. System information adalah kumpulan elemen yang saling berhubungan dan berfungsi untuk memproses, mengumpulkan, mendistribusikan serta menyimpan informasi yang berguna sebagai pendukung dalam pembuatan keputusan juga pengawasan keputusan dalam organisasi. System information yang dapat mendukung dan meningkatkan proses penjualan sangatlah dibutuhkan. (Muhammad Galang Ramadhan, 2020)

System point of sale (POS) adalah sebuah sistem aplikasi yang diterapkan pada bisnis minimarket ataupun pertokoan untuk menangani pengolahan data transaksi pembelian (purchase), transaksi penjualan eceran (retail), transaksi hutang (debt), transaksi hutang (debt), transaksi hutang (debt), transaksi hutang (debt), transaksi hutang (debt) Report) yangsecara umum penting dibutuhkan dalam pengambilan keputusanstrategik oleh para pebisnis swalayan,organisasi, atau perusahaan yang berskala kecil dan menengah [2]. Perusahaan besar maupun perusahaan menengah yang bergerak di dalam bidang perdagangan, pada umumnya akan menggunakan system POS dalam menunjang kegiatan usahanya. (Muhammad Galang Ramadhan, 2020)

Peran utama aplikasi sistem informasi dalam bisnis adalah untuk memberikan dukungan efektif atas strategi perusahaan agar dapat memperoleh keunggulan kompetitif. Peran strategis sistem informasi melibatkan penggunaan teknologi informasi adalah untuk mengembangkan berbagai produk, layanan dan kemampuan yang dapat memberikan keunggulan yang besar bagi perusahaan atas tekanan kompetitif dalam pasar global. Hal ini menciptakan sistem informasi strategis yang mendukung atau membentuk posisi kompetitif dan strategi dari perusahaan bisnis.

Dengan kata lain, perpaduan sistem informasi dengan teknologi informasi dapat membantu organisasi dalam hal:

1. Memperoleh keunggulan kompetitif

2. Mengurangi kelemahan kompetitif

3. Memenuhi tujuan srategis perusahaan 
Perusahaan dapat bertahan hidup dan berhasil dalam jangka panjang hanya jika perusahaan tersebut berhasil mengembangkan strategi untuk menghadapi tekanan kompetitif yang membentuk struktur persaingan dalam dunia usaha.

Dalam menerapkan strategi bisnis yang kompetitif, perlunya penerapan system informasi bagi perusahaan. Karena sistem informasi memiliki peran strategis antara lain:

1. Hasil potensial dari penggunaan strategi sistem informasi

2. Meningkatkan efisiensi operasional

3. Memperkenalkan inovasi bisnis

4. Membangun sumber informasi strategis

5. Meningkatkan produktivitas dan menurunkan biaya operasi produksi atau jasa baru

6. Meningkatkan kualitas dan fitur produk serta jasa.

7. Meningkatkan proses operasional dan lingkungan kerja yang efektif dan efisien.

Dalam industri retail, sistem informasi merupakan senjata yang paling penting dalam memenangkan persaingan usaha, mengingat informasi merupakan peralatan yang sangat strategis bagi perusahaan dan memerlukan biaya yang besar untuk pengadaan maka penerapannya harus dilakukan dengan perencanaan dan studi yang matang. 


\section{LANDASAN TEORI}

\section{A. Pengertian Sistem}

Sistem merupakan sekumpulan elemen, himpunan dari suatu unsur, komponen fungsional yang saling berhubungan dan berinteraksi satu sama lain untuk mencapai tujuan yang diharapkan. Kebutuhan informasi yang semakin luas, volume pengolahan data semakin meningkat, perubahan prinsip akuntansi yang baru menyebabkan harus disusunnya sistem yang baru, karena sistem yang lama tidak efektif lagi dan tidak dapat memenuhi lagi semua kebutuhan informasi yang dibutuhkan manajemen. Maka dari itu diperlukan pengembangan system.

Pengembangan sistem (systems development) merupakan menyusun suatu sistem yang baru untuk menggantikan sistem yang lama secara keseluruhan atau memperbaikis istem yang telah ada. (Prabowo, 2015)

Sistem yang lama perlu diperbaiki atau diganti disebabkan karena beberapa hal, yaitu sebagai berikut ini (Prabowo, 2015):

- Adanya permasalahan-permasalahan (problems) yang timbul di sistem yang lama.

- Ketidakberesan dalam sistem yang lama menyebabkan sistem yang lama tidak dapat beroperasi sesuai dengan yang diharapkan.

- Kecurangan-kecurangan disengaja yang menyebabkan tidak amannya harta kekayaan perusahaan dan kebenaran dari data menjadi kurang terjamin.

- Kesalahan-kesalahan yang tidak disengaja yang juga dapat menyebabkan kebenaran dari data kurang terjamin.

- Tidak efisiennya operasi.

- Tidak ditaatinya kebijaksanaan manajemen yang telah ditetapkan.

\section{B. Pengertian Sistem Informasi Manajemen}

Sistem informasi manajemen kerap disingkat dengan SIM yang berasal dari bahasa Inggris yakni management information system. Pengertian SIM adalah sistem perencanaan bagian dari pengendalian internal dalam bisnis yang terdiri atas pemanfaatan dokumen, manusia, teknologi, serta prosedur dalam akuntansi manajemen. 
Tujuannya adalah memecahkan beragam masalah dalam bisnis yang meliputi layanan, biaya produk, serta strategi bisnis. Keseluruhan sistem ini digunakan dalam rangka menganalisis sistem informasi yang lain pada penerapan aktivitas operasional suatu organisasi.

Menurut para ahli :

\section{Menurut Bodnar dan Hopwood}

Management information system adalah kumpulan perangkat keras dan perangkat lunak yang dirancang untuk mentrasformasikan data dalam bentuk informasi yang berguna.

Menurut L. Jamers Havery

Management information system adalah prosedur logis dan rasional untuk melakukan atau merancang suatu rangkaian komponen yang berhubungan satu sama lain.

\section{Menurut Azhar Susanto}

Sistem informasi manajemen merupakan kumpulan atau grup dari sub sistem atau bagian atau komponen apapun biak fisik maupun non fisik yang saling berhubungan satu sama lain dan berkenaan dengan pengendalian, pengevaluasian, dan perbaikan berkelanjutan.

\section{Menurut Ludwig Von Batalanfy}

Management information system merupakan seperangkat unsur yang saling terkait dalam suatu antar relasi diantara unsurOunsru tersebut dengan lingkungan.

\section{Manfaat Sistem Informasi Manajemen}

SIM memiliki beberapa manfaat yang penting dalam keberlangsungan organisasi atau perusahaan. Beberapa manfaatnya akan dibahas pada poin-poin di bawah ini :

1. Menyediakan informasi yang digunakan dalam penghitungan harga pokok produk, jasa, serta tujuan lain yang diinginkan oleh manajemen.

2. Menyediakan informasi yang digunakan untuk merencanakan, mengendalikan, mengevaluasi, serta melakukan perbaikan yang berkelanjutan. 
3. Menyediakan informasi dalam mengambil keputusan penting.

\section{Pengertian Swalayan}

Pasar swalayan merupakan suatu organisasi perdagangan eceran yang menawarkan berbagai macam produk yang mendalam kepada konsumen dan membagi-bagi kegiatan usahanya menjadi beberapa departemen untuk pengaturan barang dagangan.

Pasar swalayan menurut Marwan Asri (1991 : 289) adalah salah satu bentuk

usaha eceran yang menyediakan beraneka macam kebutuhan konsumen. Satu Supermarket mungkin menjual pakaian wanita, pria, anak-anak, alat rumah tangga, alat olah raga, perhiasan serta alat rumah tangga lainnya dan alat tulis.

\section{$>$ Ciri-ciri Supermarket}

Ada hal yang membedakan supermarket dengan perusahaan perdagangan eceran lainnya yaitu :

1. Supermarket menitikberatkan pada penjualan shopping Goods dan beberapa macam Specilty Goods.

2. Supermarket merupakan suatu swalayan yang besar dan membutuhkan banyak sekali tenaga kerja.

\section{Perbedaan antara minimarket, supermarket, hypermart :}

1. Minimarket

Minimarket adalah pasar swalayan yang secara ukuran toko dan jumlah item barang yang dijual lebih sedikit daripada 2 yang lainya tadi.Dimana jumlah item barang yang dijual utk minimarket antara 3000 sanpai 5000 macam barang yg dijual. Ukuran toko pun antara $300-500$ persegi,sebagai contoh lihat saja INDOMARET atau ALFAMART. Rata rata ukurannya mereka sama. Selain itu radius area yang dilayani minimarket juga tidak jauh yaitu secara efektif kurang dari $2 \mathrm{~km}$. Dan ini sudah menjadi panduan para retail minimarket. 


\section{Supermarket}

Berbeda dengan minimarket,supermarket secara fisik bangunan pasti lebih besar dibanding minimarket, karena jumlah barang yang dijual juga lebih banyak yaitu antara 5000 sampai 15000 macam barang. Contoh supermarket kalau di jawa tengah adalah LUWES, LARIS, mereka tergolong supermarket. Utk radius area yang efektif tercover sampai $10 \mathrm{~km}$.

\section{Hypermart}

Untuk yang satu ini pasti juga sudah pada tau,hypermarket adalah pasar swalayan yang terbesar baik dari ukuran fisik bangunan maupun jumlah barang yang dijual. Yang jelas diatas 15000 macam barang dagangan. Dan radius area yg bisa tercover `sampai $50 \mathrm{~km}$.

\section{Jenis Pasar Swalayan}

Selain supermarket dikenal pula minimarket, midimarket, dan hypermarket.

Perbedaan istilah minimarket, supermarket dan hypermarket adalah di format, ukuran dan fasilitas yang diberikan.

Contohnya :

- Minimarket berukuran kecil (100m2 s/d 999m2).

- Supermarket berukuran sedang (1.000m2 s/d 4.999m2).

- Hypermarket berukuran besar $(5.000 \mathrm{~m} 2 \mathrm{ke}$ atas).

- Grosir berukuran besar $(5.000 \mathrm{~m} 2 \mathrm{ke}$ atas $)$. 


\section{METODE PENELITIAN}

1. Lokasi Penelitian

Lokasi dalam penelitian ini dilakukan di swalayan-swalayan yang ada di Kabupaten Tulungagung.

2. Waktu Penelitian

Waktu yang dibutuhkan untuk melakukan penelitian ini yaitu kurang lebih selama satu bulan, terhitung sejak bulan akhir April sampai dengan bulan Juni di swalayan yang ada di Tulungagung.

3. Jenis Data

Dalam penelitian ini data yang digunakan yaitu data sekunder. Data sekunder merupakan data yang tidak berasal dari sumber utama. Data ini digunakan sebagai data pendamping data utama karena adanya hal-hal yang tidak ditemukan di data utama. Namun di beberapa penelitian lainnya, data sekunder ini menjadi satu-satunya sumber data. 


\section{PEMBAHASAN}

\section{A. Sistem yang Paling Sering Digunakan di Swalayan Tulungagung}

Pada swalayan di tulungagung system yang paling sering digunakan yaitu aplikasi POS. Point of Sales (POS) adalah suatu sistem yang digunakan oleh berbagai macam usaha ritel untuk menyelesaikan transaksi jual beli. Merupakan versi modern dari mesin kasir konvensional/cash register yang biasanya sudah dilengkapi dengan cash drawer. Sekarang POS sudah menjadi bagian yang penting dari operasional berbagai usaha, dan fungsinya pun kini sudah lebih dari sekedar untuk memproses transaksi penjualan. Seperti misalnya yaitu Bravo, Golden, Alfamart maupun Indomaret di Tulungagung semua menggunakannya.

\section{B. Cara Penggunaan POS}

Pada sistem ini terdapat dua pengguna (User) antara lain Admin dan Kasir. Admin dalam sistem ini bertugas untuk input data supplier, data pelanggan (Customer), mengelola stok yang masuk ke POS dari supplier, mengelola data pengguna (User), dan mengelola data barang. Kasir pada sistem ini bertugas memasukkan kategori barang yang tersedia, data satuan barang, melakukan transaksi dengan pelanggan, dan melakukan pencetakkan struk atau nota belanjaan. Pengguna admin pada sistem ini juga dapat mengakses semua yang ada pada sistem POS ini.

\section{a) Tampilan Halaman Login}

Tampilan halaman login merupakan tampilan awal untuk menampilkan yang dimana pengguna harus meng-input username dan password terlebih dahulu sebelum mengakses aplikasi tersebut, terdapat dua pengguna pada sistem ini yaitu Admin dan Kasir. Data yang di-input harus sesuai pada database yang sudah tersimpan username dan password pengguna. Setelah terisi, tekan button Login yang tersedia pada tampilan, dan kemudian akan masuk ke halaman menu utama atau dashboard. Tampilan sebelum masuk ke halaman menu utama adalah halaman Login.

Berikut tampilan halaman Login: 
Gambar 1 : Tampilan Halaman Login

\section{b) Tampilan Halaman Dashboard}

Terdapat tujuh menu utama yang dapat diakses sebagai pengguna admin (Gambar 2). Pada bagian Dashboard terdapat 4 data menu, antara lain Items (terletak di menu Products), Supplier, Customer, dan Users. Maksud angka dari setiap menu tersebut merupakan data yang tersimpan di database dari setiap menu-menu tersebut. Menu Supplier berisi daftar pemasok barang yang bekerjasama dengan pemilik toko, di dalam menu supplier juga dapat menambahkan data pemasok barang yang baru.

Menu Customer (Pengguna) berisi daftar pelanggan yang tersimpan pada database, fungsi dari adanya Customer ini sebagai data bagi pelanggan tetap atau member yang berbelanja di sistem POS ini. Kemudian pada menu Products memiliki Submenu yang terdiri dari Categories yang berisi daftar kategori barang yang tersedia; Units yang berisi daftar satuan barang yang tersedia; dan Items yang berisi daftar barang yang telah disimpan ke Database dari pemasok- pemasok barang. Menu Transaction pun memiliki tiga submenu yaitu Sales berisi halaman formulir penjualan yang di halaman tersebut dilakukan transaksi antara kasir dengan pembeli; Stock in yang berisi halaman daftar data stok barang yang masuk dari pemasok barang atau supplier; Stock out yang berisi halaman data stok barang yang rusak, kadaluwarsa, ataupun hilang dari pemasok barang. Pada menu Reports berisi laporan penjualan atau aktifitas transaksi yang telah dilakukan oleh kasir. Menu Users, berisi daftar data pengguna yang telah disimpan pada Database. 


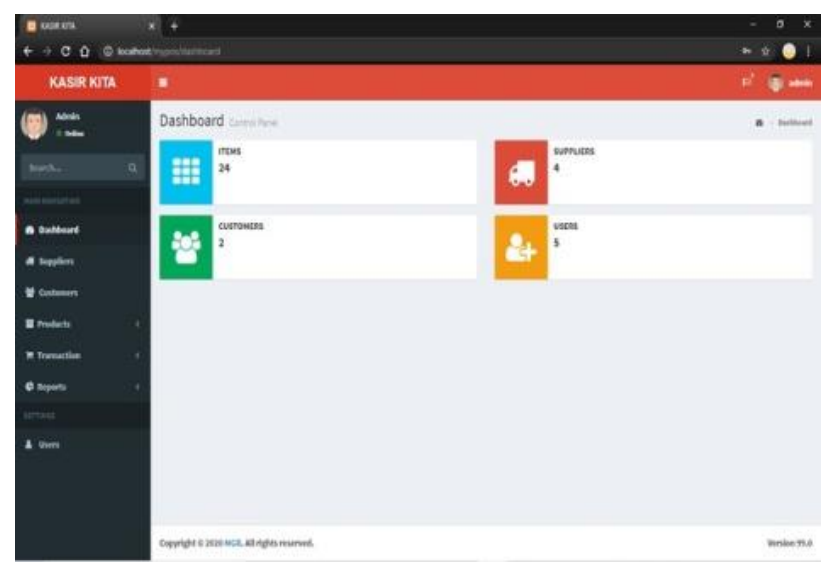

Gambar 2 : Tampilan Halaman Dashboard Admin

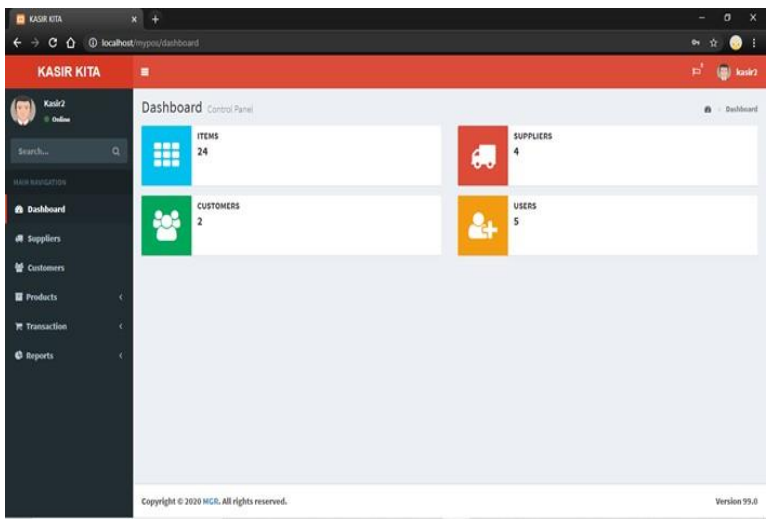

Gambar 3 : Tampilan Halaman Dashboard Kasir

Pada menu utama pengguna kasir, terlihat tidak memiliki akses ke menu Users, karena kasir tidak memiliki hak untuk merubah data dari pengguna yang tersimpan pada sistem ini. Pada menu Suppliers dan Customers, kasir hanya dapat melihat daftar data pemasok barang dan pelanggan yang tersimpan pada database yang artinya tidak memiliki hak untuk menambahkan data pemasok barang ataupun pelanggan ke database. Kemudian pada menu Transaction, kasir tidak memiliki hak untuk mengakses halaman Stock In karena sistem ini diatur agar hanya admin yang dapat menambahkan stok barang ke sistem POS.

\section{c) Tampilan Halaman Sales (Penjualan)}

Gambar 4 merupakan halaman menu transaksi penjualan, yang 
nantinya akan ada tampilan daftar barang yang di scan melalui scanner barcode. Menu ini dapat diakses oleh Admin dan Kasir, hanya saja tugas transaksi penjualan ini diserahkan ke Kasir.

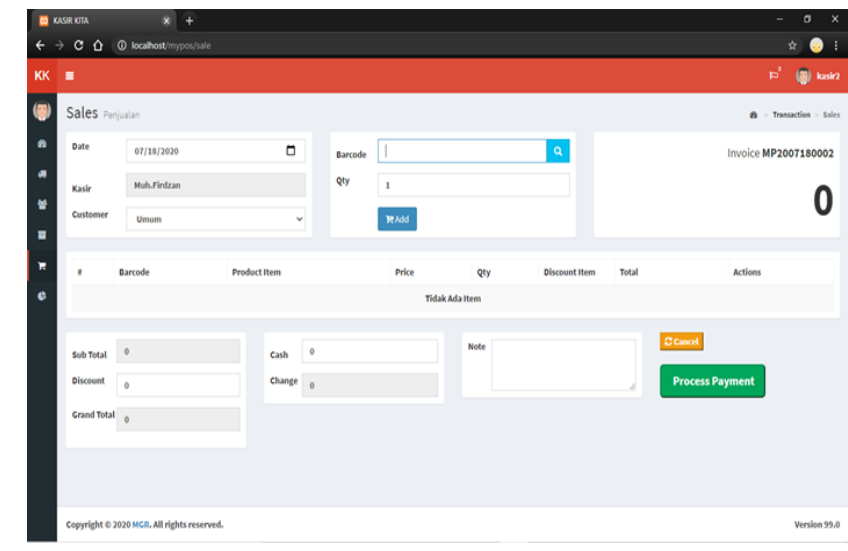

Gambar 4 : Tampilan Halaman Sales (Penjualan)

\section{Keuntungan Menggunakan POS}

\section{Meningkatkan Kepercayaan}

Sistem POS menawarkan berbagai hal positif untuk pengelola atau direktur bisnis. Sistem POS dapat meningkatkan kepercayaan pengguna dalam sejumlah cara. Misalnya, mereka tidak harus menghabiskan banyak waktu menghafal harga produk, atau secara manual memasukkan data dalam jumlah besar sebagaimana mereka lakukan pada mesin kasir biasa. Hal ini akan memungkinkan mereka untuk menawarkan layanan pelanggan yang lebih baik, yang pada akhirnya dapat memberikan perusahaan Anda basis pelanggan lebih loyal, sederhananya karena kenyataan orang yang mereka layani sudah berbicara dengan ramah, dan tenang.

Menggunakan sistem POS dengan scanner barcode secara signifikan akan mempercepat proses check-out. Ini memberikan kemampuan untuk mengenali pelanggan setia dan menghargai mereka atas dukungan mereka. Hal ini dapat dengan mudah mengumpulkan data pelanggan (dari transaksi kartu kredit) yang dapat digunakan untuk program iklan dan insentif yang ditargetkan.

\section{Mengurangi Tingkat Kesalahan}

Aplikasi POS berguna untuk mengurangi beberapa kesalahan yang terjadi seperti penginputan data dan hal lainya yang berkaitan dengan transaksi dan 
pelaporanya. Dengan menggunakan aplikasi pos kita dapat meminimalisir kesalahan yang terjadi baik itu dari missing input ataupun out put.

\section{Aplikasi POS Meningkatkan Efisiensi}

Saat ini efisiensi waktu sangat dibutuhkan dalam bisnis, karena semakin banyak transaksi semakin cepat juga kebutuhan untuk penginputanya. Dengan menggunakan aplikasi POS kita bisa mendapatkan efisiensi waktu yang lebih tinggi, karena dengan proses ini user hanya tinggal menggunakan aplikasi yang serba otomatis, mudah dan cepat.

Mempercepat keseluruhan proses transaksi tidak hanya membuat hidup lebih mudah bagi staf, itu juga berarti omset lebih cepat, lebih efisien dan dengan potensi untuk lebih banyak pelanggan per jam, ini tentu akan membantu meningkatkan pendapatan perusahaan dalam jangka panjang.

\section{Manajemen Stok}

Untuk bisnis yang menggunakan sistem pendekatan secara tradisional untuk manajemen stok memerlukan pedagang untuk secara fisik meninjau tingkat stok mereka saat ini secara berkala. Tentu hal ini bisa menjadi proses yang memakan tenaga dan waktu, terutama untuk bisnis skala besar.

Titik modern sistem penjualan memungkinkan semua saham yang akan dipindai pada saat pengiriman dan dimasukkan ke dalam database digital. Oleh karena itu, pedagang dapat meninjau tingkat stok mereka secara keseluruhan dalam sekejap dan membuat keputusan pembelian yang sesuai akurat.

\section{Aplikasi POS untuk Pelacakan Karyawan}

Kadang para pebisnis selalu was-was dengan kinerja dari karyawanya, kadang pimpinan tidak selalu ada di tempat dan berpindah-pindah melakukan aktivitasnya. Jadi dengan adanya Aplikasi POS, kita bisa memantau kinerja karyawan. Karena data akan otomatis terupload menuju cloud dan terhubung ke aplikasi pusat. 
D. Fitur-Fitur Mesin Kasir vs Point Of Sale (POS)

$\begin{array}{ll}\text { Fitur Mesin Kasir } & \text { Fitur Point } \text { Of Sale (POS) } \\ \text { Laci uang tunai. } & \text { Laci uang tunai. } \\ \text { Pencetak struk penjualan. } & \text { Pencetak struk penjualan. } \\ \text { Pemindah barcode. } & \text { Pemindah barcode. } \\ \text { Tombol NS (No Sale). } & \text { Tombol NS (No Sale) dan password. } \\ & \text { Pembaca kartu kredit. } \\ & \text { Timbangan digital. } \\ & \text { Manajemen staf dan konsumen. } \\ & \text { Pelacak persediaan stok barang. } \\ \text { Laporan penjualan sederhana. } & \text { Laporan penjualan lengkap. } \\ \text { Sistem berbasis cloud. } \\ \text { Layar sentuh. } \\ \text { Terintegrasi dengan software akuntansi } \\ \text { dan software lainnya. }\end{array}$

Mesin kasir manual sederhana mungkin cocok untuk beberapa bisnis kecil. Namun, agar lebih kompetitif serta pengelolaan bisnis yang lebih efisien, Anda perlu mempertimbangkan untuk menggunakan sistem Point Of Sale (POS).

\section{E. Software POS yang Terintegrasi dengan Jurnal}

\section{a. iREAP POS Pro}

Software ini sangat cocok bagi Anda yang sedang menjalankan bisnis retail, franchise, kafe, restoran dan lain sebagainya. iREAP POS dengan kolaborasinya dengan Jurnal dapat menerima laporan penjualan secara otomatis, mengelola barang dan harga hingga mengontrol stok dan kasir penjualan. 


\section{b. Moka POS}

Dengan menghubungkan Moka POS dan Jurnal, Anda bisa menerima laporan penjualan secara otomatis. Semua transaksi penjualan yang tercatat dalam aplikasi Moka POS itu nantinya akan secara otomatis tercatat dalam pembukuan bisnis Anda.

\section{c. Oktopus POS System}

Menggabungkan Oktopus dengan Jurnal akan mempermudah Anda dalam melakukan pencatatan penjualan. Jurnal pun nantinya akan langsung menyiapkan laporan penjualan hingga laporan keuangan secara cepat dan tepat.

\section{d. Vend POS}

Sistem Jurnal dan VendPOS yang sama-sama mudah digunakan dalam proses penjualan dan pencetakan laporan penjualan serta pembayaran membuat Anda secara mudah melakukan pembukuan bisnis secara online kapanpun dan di mana pun.

\section{e. POS iSeller}

Dan yang terbaru adalah integrasi Jurnal dengan iSeller yang dapat mensinkronisasikan data-data produk, penjualan, hingga inventory dari POS iSeller kepada Jurnal.

Penggunaan sistem Point Of Sale (POS) memang tergantung pada bisnis tersebut. Namun jika ingin bisnis Anda terkelola dengan rapi baik masalah transaksi, manajemen produk, karyawan, pembukuan dan sistem akuntansi lainnya maka sistem ini merupakan pilihan tepat. 


\section{KESIMPULAN DAN SARAN}

Sistem informasi swalayan dapat menjadi salah satu solusi yang dapat digunakan untuk memantau dan mempermudah penjual, pembelian dan retur pembelian dalam mengolah data barang, serta membuat laporan penjualan, pembelian dan retur pembelian dengan lebih mudah, cepat dan akurat. Hasil pengolahan data-data pada sistem informasi Swalayan berupa laporan data barang, laporan data supplier, laporan data penjualan barang, laporan pembelian retur pembelian dan grafik. Dengan adanya sistem komputerisasi yang baru, maka pengolahan data transaksi pembelian dan penjualan akan lebih cepat dan akurat. Setelah sistem informasi swalayan dibuat ada beberapa saran yang berhubungan dengan sistem informasi. Perangkat lunak yang dibuat ini sifatnya masih standar, perlu adanya penambahan kelengkapan-kelengkapan untuk dapat diimplementasikan pada dunia nyata, yaitu pada suatu perusahaan-perusahaan yang benar benar akan jalur transaksi pembelian dan penjualan yang padat. Setiap operator memperhatikan dalam penggantian password pada perangkat lunak, untuk menjaga keamanan data yang ada. Menyarankan agar perangkat lunak yang dibuat, dapat dipergunakan dalam perusahaan untuk mempermudah dan mempercepat pekerjaan dalam pengolahan data untuk masalah pembelian barang dan penjualan barang. Agar sistem informasi penjualan barang dapat ditampilkan dengan optimal, maka perlu didukung oleh hardware dan software yang memadai. Sistem informasi dapat dikembangkan lagi dengan menambahkan fasilitas-fasilitas lain yang dapat membuat sistem menjadi lebih. Basis data yang digunakan sebaiknya selalu mengalami perubahan dalam periode tertentu agar selalu up to date. 


\section{DAFTAR PUSTAKA}

Muhammad Galang Ramadhan. (2020). Perancangan Sistem Informasi Pos (Point of Sales) Berbasis Web Dengan Menggunakan Framework Codeigniter Pada Pasar Swalayan. Electrician, 14(3), 76-83. https://doi.org/10.23960/elc.v14n3.2155

Prabowo, R. G. M. (2015). Pengembangan Sistem.

https://penalaran-unm.org/jenis-jenis-data-penelitian/

https://www.jurnal.id/id/blog/mesin-kasir-vs-point-of-sale/\#Fitur-

Fitur_Mesin_Kasir_dan_Point_Of_Sale_POS 